\title{
HISTORIA DE LAS MATEMÁTICAS EN LA EDUCACIÓN MATEMÁTICA: LA IMPORTANCIA DE EXPLICITAR LAS POSICIONES TEÓRICAS ${ }^{1}$
}

\author{
Bernadete Barbosa Morey ${ }^{1}$ \\ bernadetemorey@gmail.com \\ Valdenize Lopes do Nascimento ${ }^{1,2}$ \\ denizeln@ufersa.edu.br \\ ${ }^{1}$ Universidade Federal do Rio Grande do Norte \\ ${ }^{2}$ Universidade Federal Rural do Semi-Árido
}

Recibido: 24/11/2019 Aceptado: 22/01/2020

\section{Resumen}

Este artículo tiene como objetivo proponer la explicación de un elemento más en el debate sobre las relaciones entre la Historia de las Matemáticas y la Educación Matemática. Primero examinamos la pregunta de por qué, cuando estudiamos matemáticas en el siglo XXI, nos referimos a la historia de las matemáticas. Participamos en este debate apoyados por la posición de Luis Radford, autor de la Teoría de la Objetivación, una teoría de la enseñanza y el aprendizaje de la corriente sociocultural y el filósofo Evald Ilyenkov y su concepto de realidad como un proceso preñado de historicidad. Pero es el recapitulacionismo expuesto por Antonio Miguel y Maria Ângela Miorim en História na Educação Matemática: propostas e desafios lo que nos da pistas para ir más allá y argumentar que en estudios relacionados con la Historia de las Matemáticas y la Educación Matemática tiene perfecto sentido hacer explícita la teoría del aprendizaje o incluso la visión de las matemáticas y el aprendizaje que se asume para evitar la suposición de que el recurso a la Historia de las Matemáticas que se propone tiene sentido universal.

Palabras clave: Historia de las Matemáticas, Educación Matemática, Recapitulacionismo, Aprendizaje, Teoría de la Objetivación.

\section{HISTORY OF MATHEMATICS IN MATHEMATIC EDUCATION: THE IMPORTANCE OF EXPLICITING THEORETICAL POSITIONS}

\begin{abstract}
This article aims to propose the explanation of one more element in the debate about the relations between History of Mathematics and Mathematical Education. We first examine the question of why, when studying mathematics in the 21 st century, refer to the history of mathematics. We took part in this debate supported by the position of Luis Radford, author of Theory of Objectification, a theory of teaching and learning of the sociocultural current and the philosopher Evald Ilyenkov and his concept of reality as a pregnant process of historicity. But it is the recapitulationism expounded by Antonio Miguel and Maria Ângela Miorim in História na Educação Matemática: propostas e desafios that gives us clues to go further and
\end{abstract}

${ }^{1}$ Uma versão simplificada deste artigo foi publicada nos Anais do ENEM 2019. 
argue that in studies relating the History of Mathematics and Mathematical Education it makes perfect sense make explicit the theory of learning or even the view of mathematics and learning that is being assumed so as to avoid the assumption that the recourse to the History of Mathematics being proposed makes universal sense.

Keywords: History of Mathematics, Mathematical Education, Recapitulationism, Learning, Theory of Objectification.

\title{
HISTÓRIA DA MATEMÁTICA NA EDUCAÇÃO MATEMÁTICA: A IMPORTÂNCIA DE EXPLICITAR AS POSIÇÕES TEÓRICAS
}

\begin{abstract}
Resumo
O presente artigo tem como objetivo propor a explicitação de um elemento a mais no debate em torno das relações entre História da Matemática e Educação Matemática. Inicialmente examinamos a questão do porquê, ao estudar a matemática em pleno século XXI, reportar-se à História da Matemática. Participamos deste debate apoiadas na posição de Luis Radford, autor da Teoria da Objetivação, uma teoria de ensino e aprendizagem da corrente sociocultural e no filósofo Evald Ilyenkov e seu conceito de realidade como um processo prenhe de historicidade. Mas é o recapitulacionismo exposto por Antonio Miguel e Maria Ângela Miorim em História na Educação Matemática: propostas e desafios que nos dá pistas para ir mais adiante e defender que nos estudos que relacionam História da Matemática e Educação Matemática faz todo sentido explicitar a teoria de aprendizagem ou mesmo a visão de matemática e de aprendizagem que está sendo pressuposta, de modo a evitar a suposição que o recurso à História da Matemática que está sendo proposto faça sentido universalmente.

Palavras-chave: História da Matemática, Educação Matemática, Recapitulacionismo, Aprendizagem, Teoria da Objetivação.
\end{abstract}

\section{INTRODUÇÃO}

$\mathrm{Na}$ sociedade contemporânea é indiscutível a importância da Matemática para o desenvolvimento da Ciência e da Tecnologia, bem como para a formação do cidadão. Infelizmente, é indiscutível também que existem muitos problemas relacionados ao processo de ensino-aprendizagem desta complexa ciência, em todos os níveis educacionais. O renomado pesquisador da Educação Matemática Ubiratan D’Ambrosio destaca que:

A complexidade da Matemática, sobretudo por suas relações com outras áreas de conhecimento e por suas implicações sociais, políticas e econômicas, justifica, desde a Antiguidade, reflexões, teorias e estudos sobre seu ensino. (D’Ambrosio, 1993, p. 9-10)

As preocupações com o processo de ensino-aprendizagem da matemática continuam pujantes e as reflexões sobre esse tema têm acarretado uma busca constante por recursos pedagógicos que possam ser utilizados para melhoria desse processo. Dentre os recursos 
pedagógicos em evidência na Educação Matemática (EM) atualmente está a História da Matemática (HM), considerada uma de suas tendências.

Muitas pesquisas envolvendo as relações entre HM e EM vêm sendo desenvolvidas, tanto nacional quanto internacionalmente, e muitos são também os argumentos que destacam a importância da História da Matemática para o ensino-aprendizagem dos saberes matemáticos. Diversas são as abordagens e diversos são os benefícios alegados que a HM pode trazer para o ensino-aprendizagem da Matemática, mas, o debate sobre esta temática continua.

Queremos neste artigo contribuir para o debate enfatizando a importância de explicitar as posições teóricas utilizadas para justificar o vínculo entre os saberes matemáticos produzidos historicamente e a aprendizagem desses saberes no presente e também trazendo aqui a posição teórica assumida pelo professor e pesquisador canadense Luis Radford, cuja visão sobre o papel da HM na EM está estreitamente ligada ao arcabouço teórico da Teoria da Objetivação (TO), teoria de ensino-aprendizagem da qual é autor.

Este artigo está estruturado em cinco seções, sendo esta introdução a primeira. Na segunda seção apresentamos um breve histórico do debate em torno das relações entre HM e EM a partir de uma fonte pela qual se pode acompanhar as discussões contemporâneas sobre a temática em foco. Na terceira seção apresentamos e discutimos alguns argumentos envolvendo o papel da HM na EM, a partir dos estudos do pesquisador Antonio Miguel. Na quarta seção abordamos a relação entre os saberes matemáticos produzidos historicamente e a aprendizagem desses saberes no presente. Na quinta seção apresentamos a posição teórica de Luis Radford acerca do papel da HM na EM, a qual, está estreitamente ligada ao arcabouço teórico da Teoria da Objetivação. Concluímos o artigo com algumas considerações sobre as discussões apresentadas e sobre o potencial da HM para a EM no século XXI.

\section{BREVE HISTÓRICO DO DEBATE EM TORNO DAS RELAÇÕES ENTRE HISTÓRIA DA MATEMÁTICA E EDUCAÇÃO MATEMÁTICA}

Para um breve histórico do debate envolvendo as relações entre HM e EM consideramos pertinente tomar como base a recente publicação de Clark et al. (2016), que descreve o estado da arte sobre o papel da HM na EM, tema do Grupo de Estudo Temático (Topic Study Group - TSG) no 25 do XIII Congresso Internacional de Educação Matemática (International Congress on Mathematical Education - ICME 13), e "fornece um breve relato 
dos desenvolvimentos desde $2000^{2}$ sobre as relações entre História e Pedagogia da Matemática.” (Clark et al., 2016, p. 135, tradução nossa)

De acordo com os autores, a questão da integração da HM com a EM vem sendo debatida desde a segunda metade do século XIX, quando matemáticos como Augustus De Morgan (1806 - 1871), Henri Poincaré (1854 - 1912) e Felix Klein (1849 - 1925), dentre outros, viram com bons olhos e passaram a apoiar a integração destes dois domínios. Posteriormente, os historiadores Paul Tannery (1843 - 1904) e Gino Benedetto Loria (1862 1954) também vieram a se interessar ativamente pelo papel que a HM pode exercer na EM.

No início do século XX o debate foi revivido, impulsionado pelos debates sobre os fundamentos da matemática. No período 1960-1980, como consequência da reforma da Matemática Moderna, o interesse no debate sobre o papel da HM na EM se fortaleceu ainda mais, pois, enquanto os proponentes da reforma se posicionavam contra uma abordagem histórica da EM, os críticos dessa reforma viam na HM um remédio contra o dogmatismo e concebiam a matemática como uma atividade humana e não apenas como uma linguagem.

Outro momento importante para a consolidação dos estudos na temática em foco tem início em 1969 quando o $31^{\circ}$ anuário do Conselho Nacional de Professores de Matemática (National Council of Teachers of Mathematics - NCTM) nos Estados Unidos, foi dedicado à HM como recurso para o ensino.

Na década de 1970 um movimento internacional começou a se propagar, em grande parte apoiado pela criação em 1972 do Grupo de Estudos Internacional sobre as Relações entre a História e a Pedagogia da Matemática (HPM Group) afiliado à Comissão Internacional de Instrução Matemática (International Commission on Mathematical Instruction - ICMI), por ocasião da segunda edição do ICME.

Nos últimos 40 anos, ainda de acordo com Clark et al. (2016), a questão da integração da HM à EM evoluiu para uma área de estudos na qual novas práticas pedagógicas e atividades de pesquisa específicas se estabeleceram internacionalmente. O marco que forneceu mais visibilidade a estas discussões foi a publicação no ano de 2000 da obra History in Mathematics Education: The ICMI Study, editado por John Fauvel e Jan van Maanen (ver Fauvel \& van Maanen (2000)), uma obra coletiva escrita por 62 colaboradores que trabalharam juntos distribuídos em 11 grupos. Esta obra também contribuiu fortemente para

\footnotetext{
${ }^{2} \mathrm{O}$ ano de publicação da obra History in Mathematics Education: The ICMI Study.
} 
estimular e intensificar o interesse da comunidade educacional internacional sobre esta temática.

Em se tratando dos estudos no Brasil, podemos citar como grandes pioneiros e incentivadores das gerações mais jovens, nomes como: Ubiratan D'Ambrosio, Eduardo Sebastiani, Antonio Miguel, dentre outros. Um estudo que se tornou referência nacional foi a tese de doutorado do pesquisador Antonio Miguel, intitulada Três Estudos sobre História e Educação Matemática de 1993. Na tese são apresentados três estudos sobre a relação entre HM e EM cujos objetivos são explicitar e fundamentar três pontos de vista do pesquisador envolvendo três formas possíveis que essa relação assume.

No estudo de Miguel, a primeira forma que a relação entre HM e EM se manifesta é nos papeis atribuídos à História da Matemática a fim de tornar mais eficiente o ensino e o aprendizado da matemática. Nas palavras do pesquisador, a primeira forma de manifestação se refere "às possibilidades de se recorrer à história como um recurso pedagógico adicional, isto é, como um meio potencialmente rico para se promover o ensino-aprendizagem da matemática." (Miguel, 1993, p. 12).

A possibilidade de usar a história como recurso pedagógico foi enunciada e divulgada por professores e pesquisadores sempre acompanhada de argumentos que pareciam convincentes. Foi pensando nisto que Miguel se dispôs a olhar detalhadamente cada um dos argumentos usados a favor do uso da História como recurso pedagógico e ao mesmo tempo analisar alguns argumentos formulados contra. Assim, o primeiro estudo se propôs a:

[...] resgatar a própria história dessa forma de relação através do levantamento, detalhamento e análise dos diferentes papéis pedagógicos atribuídos à história por matemáticos, historiadores da matemática e educadores matemáticos que, de modo direto ou indireto, acabaram expressando suas posições em relação a essa questão. (Miguel, 1993, p. 16)

O segundo estudo tratava "de recorrer à história e à filosofia da matemática e à história e à filosofia da educação na tentativa de reconstituir alguns aspectos da história e da filosofia da educação matemática.” (Miguel, 1993, p. 18). Já o terceiro estudo tinha por objetivo "apresentar e discutir um estudo histórico-pedagógico-temático sobre os números irracionais", que tratava de "mostrar como a história pode operar em um nível temático bastante específico da matemática e revelar todo o seu potencial cultural, humano e educativo mais amplo." (Miguel, 1993, p. 29) 
No presente artigo nos interessa mais de perto, o primeiro dos estudos citados, pois, é deste debate que queremos participar. Na sessão seguinte trazemos uma breve apresentação sobre o teor de alguns argumentos envolvendo a participação da HM como recurso pedagógico na EM, conforme estudos realizados por Antonio Miguel.

\section{A HISTÓRIA DA MATEMÁTICA COMO RECURSO PEDAGÓGICO NA EDUCAÇÃO MATEMÁTICA}

Miguel (1997) apresenta um levantamento dos argumentos em voga sobre a participação da HM como recurso pedagógico na EM até os anos finais do século XX. O autor examina com detalhes não apenas os argumentos que reforçam o papel pedagógico da HM, mas também alguns argumentos que o questionam. Apresentamos a seguir apenas os argumentos que reforçam o papel pedagógico. Estes são diversos mas, o mais difundido é o argumento da motivação.

Sobre o argumento da motivação Miguel ressalta que:

Os partidários desse ponto de vista acreditam que o conhecimento histórico dos processos matemáticos despertaria o interesse do aluno pelo conteúdo que está sendo ensinado. Os mais ingênuos acabam atribuindo à história um poder quase mágico de modificar a atitude do aluno em relação à matemática. [...] o poder motivador da história é atestado e exaltado em função da adoção de uma concepção lúdica ou recreativa da mesma. É a história-anedota vista como contraponto momentâneo necessário aos momentos formais do ensino, que exigiriam grande dose de concentração e esforço por parte do aprendiz. Essa história-anedota, de caráter estritamente factual, quando incorporada de forma episódica nas aulas de matemática, adquiriria, segundo esses autores, uma função didática de 'relax' - a recompensa [...] [repousante] merecida e necessária pelo esforço estafante requerido pela aprendizagem da matemática; tudo se passaria como se a matemática exigisse o pensamento e a seriedade, enquanto a história aliviaria a tensão e confortaria. (Miguel, 1997, p. 75)

Miguel (1997, p. 76) refuta este suposto potencial motivador da história argumentando inicialmente que "se fosse esse o caso, o ensino da própria história seria automotivador." E segue dizendo que:

Não é isso, porém, o que atestaria a maioria dos professores de história os quais se defrontam em seu cotidiano não apenas com o desinteresse de seus alunos por esse campo do saber, como também com a enorme dificuldade de fazer com que eles compreendam a sua importância, a sua natureza, os seus objetivos e os seus métodos. (Miguel, 1997, p. 76) 
Em seguida ele destaca que "um argumento mais especializado contra esse suposto potencial motivador da história pode ser buscado no terreno da psicologia, [...] em uma de suas áreas específicas que tem por objeto de estudo a motivação.” (Miguel, 1997, p. 76)

Trouxemos aqui o primeiro e mais difundido dos argumentos de modo mais detalhado, porque queremos dar ao leitor a ideia do que se trata. No entanto, não vem ao caso fazer o mesmo com todos os argumentos posteriores, de modo que vamos apenas citá-los.

Os demais argumentos que atribuem à HM o papel de recurso pedagógico na melhoria do ensino e aprendizagem da matemática, conforme Miguel (1997), apontam a HM como:

1. Uma fonte de métodos, problemas e objetivos de ensino, o que permitiria ao professor de matemática beber da fonte HM para enriquecer suas aulas nas três direções apontadas, isto é, do ponto de vista de objetivos de ensino, do ponto de vista de metodologia de ensino e ainda extrair dali problemas históricos relevantes para o ensino.

2. Um instrumento de desmistificação da matemática e desalienação de seu ensino, uma vez que o processo histórico mostra a matemática sendo feita por homens, com todas as qualidades e defeitos de uma construção humana.

3. Um meio efetivo de formalização de conceitos matemáticos, uma vez que a história permite seguir o curso de como um conceito se forma e se estabelece.

4. Um instrumento de promoção do pensamento independente e crítico, uma vez que desmitificando a matemática e vendo-a como uma criação humana, o aluno se inclui no rol daqueles que podem opinar sobre a matemática e, até quem sabe, fazer contribuições.

5. Um meio de unificação dos vários campos da matemática. Na verdade, a matemática é um campo de conhecimento único. O seu ensino na academia é feito separando-a em disciplinas estanques, o que leva o aluno a pensar nela como sendo em partes separadas. O estudo da HM viria a mostrar o contrário, isto é, mostraria a unidade da matemática.

6. Um instrumento de promoção de atitudes e valores. Aqui, os defensores deste argumentos apontam que conhecer as biografias e o trabalho dos grandes matemáticos pode incentivar os alunos a não desistir diante das dificuldades.

7. Um instrumento de conscientização epistemológica, o que se refere ao progressivo amadurecimento intelectual do aprendiz de matemática com a concomitante compreensão por parte dele do porquê da exigência dos padrões de rigor exigidos atualmente. 
Um último argumento citado por Miguel é o que aponta a HM como um instrumento que possibilita o resgate da identidade cultural. Tal argumento se apoia mais que tudo em estudos como o de Paulus Gerdes, que mostra como a HM pode ser usada para que o aprendiz se sinta incluído entre os povos que fizeram matemática.

Aqui concluímos a apresentação dos argumentos defensores da presença da HM na EM trazidos por Antonio Miguel. Na próxima sessão nos debruçaremos sobre uma questão que emergem ao considerarmos a HM como recurso pedagógico para o ensino-aprendizagem da matemática.

\section{SOBRE A RELAÇÃO ENTRE OS SABERES MATEMÁTICOS PRODUZIDOS HISTORICAMENTE E A APRENDIZAGEM DESSES SABERES NO PRESENTE}

Ao considerar a História da Matemática como recurso pedagógico para o ensinoaprendizagem da matemática emerge, inevitavelmente, a questão do vínculo entre os saberes matemáticos produzidos historicamente e a aprendizagem desses saberes no presente. Diante disto, consideramos importante que sejam explicitadas as posições teóricas utilizadas para fundamentar este vínculo. Nos referimos mais precisamente a explicitação da concepção de aprendizagem que é adotada e a concepção de como os saberes matemáticos são produzidos historicamente. Ao nosso ver, a explicitação destas posições teóricas permitiriam um uso mais eficiente e consciente da história, uma vez que uma proposta didática construída a partir de uma concepção de aprendizagem específica não é necessariamente utilizável em uma outra concepção de aprendizagem. Por exemplo, uma proposta didática construída a partir da abordagem construtivista, não poderia ser aplicada diretamente (se é que poderia o ser de algum modo) à uma aula na qual se pretende utilizar uma abordagem sociocultural. E sabemos que não é incomum que os professores tentem utilizar propostas didáticas produzidas por outros professores.

Nossa atenção para a necessidade de explicitação destas posições teóricas foi despertada a partir de estudos realizados por Antonio Miguel, Maria Ângela Miorim, Fulvia Furinghetti e Luis Radford.

Em uma publicação conjunta, Miguel e Miorim destacam que:

No final do século XIX, a maior parte da literatura que havia sido produzida em relação à discussão acerca da participação da história no processo de ensino-aprendizagem da Matemática escolar recorria ao chamado princípio 
genético - um tipo particular de princípio recapitulacionista - como um modo aparentemente sensato e natural de se justificar essa participação. (Miguel e Miorim, 2004, p. 73)

Em uma publicação mais recente, Antonio Miguel relata que em estudos posteriores à sua pesquisa de doutorado, finalizada em 1993, por ocasião de sua participação em uma mesa redonda durante o VI ENEM (Encontro Nacional de Educação Matemática) realizado em 1998, ao retomar suas reflexões sobre as relações entre história e ensino-aprendizagem da matemática, foi possível perceber que:

Grande parte, senão a totalidade, dos argumentos aparentemente distintos geralmente utilizados para reforçar as potencialidades pedagógicas da história estariam baseados no pressuposto de que o ensino-aprendizagem da matemática deveria funcionar como um 'espelho' mais ou menos fiel da história da matemática. (Miguel, 2015, p. 2)

Tal pressuposto tem sua origem na versão psicológica da lei da recapitulação biológica do alemão Ernst Haeckel (1834 - 1919) a qual, de acordo com Furinghetti e Radford, “deu origem a um discurso que enquadrou grande parte das discussões sobre o desenvolvimento infantil desde o início do século XX." Esses autores destacam ainda que "a recapitulação psicológica foi adotada por alguns eminentes matemáticos que, de uma forma ou de outra, apoiaram a ideia de que, ao desenvolver seu pensamento matemático, as crianças atravessariam etapas semelhantes àquelas encontradas na história da matemática." Nesta concepção, “durante o seu desenvolvimento, as crianças supostamente enfrentariam alguns problemas, dificuldades ou obstáculos semelhantes aos encontrados pelos matemáticos do passado". Esta é uma visão na qual, os "desenvolvimentos conceituais são vistos como cronologicamente autoexplicativos e a evolução psicológica é tida como certa." Além disso, nesta visão, "o conhecimento é concebido como tendo pouco (se algum) vínculo com seu contexto e a história é reduzida a uma sequência linear de eventos julgados a partir do ponto de vista do observador moderno." (Furinghetti; Radford, 2008, p. 649, tradução nossa)

Dois exemplos típicos desta visão, abordados por Furinghetti e Radford (2008) e por Miguel (2015), são as perspectivas histórico-epistemológicas desenvolvidas por Jean Piaget e Rolando García na obra Psicogênese e história das ciências (Ver Piaget e García (2011)) e por Gaston Bachelard na obra A formação do espírito científico (Ver Bachelard (1996)).

Ao analisarmos os argumentos apresentados na seção anterior é possível verificar que estes argumentos continuam em voga atualmente (principalmente nos discursos dos 
professores de matemática), basta observar por exemplo os relatos de experiência referentes aos usos pedagógicos da HM, apresentados em eventos que contemplam esta temática em algum de seus eixos articuladores. Portanto, se como Miguel destaca, grande parte destes argumentos estão fundamentados em algum tipo de Recapitulacionismo, corremos o risco de estar admitindo e propagando visões equivocadas do vínculo entre a produção de saberes matemático e a aprendizagem destes saberes. Daí nossa preocupação com a explicitação das posturas teóricas utilizadas.

Aqui concluímos nossa breve discussão sobre a relação entre os saberes matemáticos produzidos historicamente e a aprendizagem. Na próxima sessão nos debruçaremos sobre o posicionamento teórico de Luis Radford.

\section{A HISTÓRIA DA MATEMÁTICA COMO UMA NECESSIDADE PARA COMPREENSÃO DA REALIDADE}

No artigo Beyond Anecdote and Curiosity, publicado em 2008, Radford discute a relevância, para o cidadão do século XXI, da dimensão histórica da Educação Matemática. Ele inicia suas reflexões levantando a questão do por que seria importante, em nosso ensino moderno de matemática, recorrer à história. Ele mesmo inicia uma série de respostas que vêm sendo dadas nos últimos anos.

A primeira destas respostas diz que a História (da Matemática) seria útil para motivar alunos e professores. Segundo Radford, como muitos alunos (e professores!) acham a matemática misteriosa e uma chateação, então a história da matemática na forma de biografias de matemáticos pode ter um papel motivacional. Radford continua dizendo que se poderia usar as obras ${ }^{3}$ de Charraud sobre George Cantor e Astruc sobre Evariste Galois, ambas de 1994, para destacar os aspectos humanos e sociais que cercam o pensamento matemático criativo. Apesar de concordar com o argumento motivacional, Radford é categórico em dizer que, no entanto, a história é mais que isto.

Uma segunda tentativa de resposta é que a história pode fornecer um panorama que vai além dos meros aspectos técnicos da matemática contemporânea, ou seja, ela possibilita a discussão da história de certos problemas, terminando por ser uma maneira interessante de

\footnotetext{
${ }^{3}$ Estas obras estão devidamente referenciadas em Radford (2008).
} 
sensibilizar os estudantes para a natureza mutável da matemática e enfatizar as contribuições de diferentes culturas. Mas outra vez, Radford diz que a história é muito mais que isto.

Um terceiro argumento oferecido é que a história pode ser uma ferramenta que permite ao professor entender melhor o desenvolvimento do pensamento matemático dos alunos. Radford reconhece que há alguns anos ele mesmo defendia este argumento, porém, agora ele o acha terrivelmente incompleto.

Para Radford, uma abordagem satisfatória para esta questão seria reconhecer a história como uma necessidade. Assumindo o pensamento do filósofo russo Evald Ilyenkov (1982) ele argumenta que a história é uma necessidade porque somente através de uma abordagem histórica é possível alcançar uma concreta compreensão da realidade.

A realidade não pode ser compreendida pela simples observação, nem pela simples aplicação de conceitos, não importa o quão sutis sejam suas ferramentas conceituais. As configurações da realidade a cada momento estão ligadas numa espécie de sistema orgânico contínuo àquelas camadas histórico-conceituais que tornaram a realidade o que ela é. A realidade não é uma coisa, mas é um processo que mesmo sem ser percebido, retrocede discretamente a todo momento aos pensamentos e ideias das gerações anteriores. A história está embutida na realidade. (Radford, 2008, p. 164, tradução nossa)

Para ilustrar esta ideia, Radford recorre à seguinte imagem (Figura 1), que "mostra como as formigas mirmíceas realizam um intercâmbio ${ }^{4}$ de substâncias estomacais" todas as vezes que se encontram. Na ilustração utilizada por Radford, a formiga da esquerda "representa o desenvolvimento filogenético dos conceitos e valores éticos, estéticos, científicos, matemáticos e outros que encontramos na cultura em que vivemos e crescemos" e a formiga da direita "representa o nosso desenvolvimento individual conceitual sociocultural ao longo de nossas vidas", ou seja, representa nosso desenvolvimento ontogenético. Nesta comparação metafórica sugerida por Radford, o que a formiga da direita está adquirindo seria "uma espécie de kit cultural-conceitual contendo linguagem, símbolos, crenças sobre como o mundo é, como deve ser investigado, etc." Isto significa que, "ao crescer, estamos continuamente recorrendo ao passado." (Radford, 2008, p. 164, tradução nossa)

\footnotetext{
${ }^{4} \mathrm{O}$ mecanismo de acoplamento entre as formigas mirmíceas, caracterizadas como insetos sociais, estabelece "um fluxo contínuo de secreções entre os membros de uma colônia - [elas] trocam seus conteúdos estomacais todas as vezes que se encontram", o que pode ser notado quando se observa "uma fileira de formigas na cozinha." Este intercâmbio contínuo de substâncias estomacais determina a especificação e diferenciação dos papéis de cada membro da colônia. (Maturana; Varela, 1995, p. 211)
} 
Figura 1. Conexão entre ontogênese e filogênese através da metáfora das formigas mirmíceas utilizada por Radford

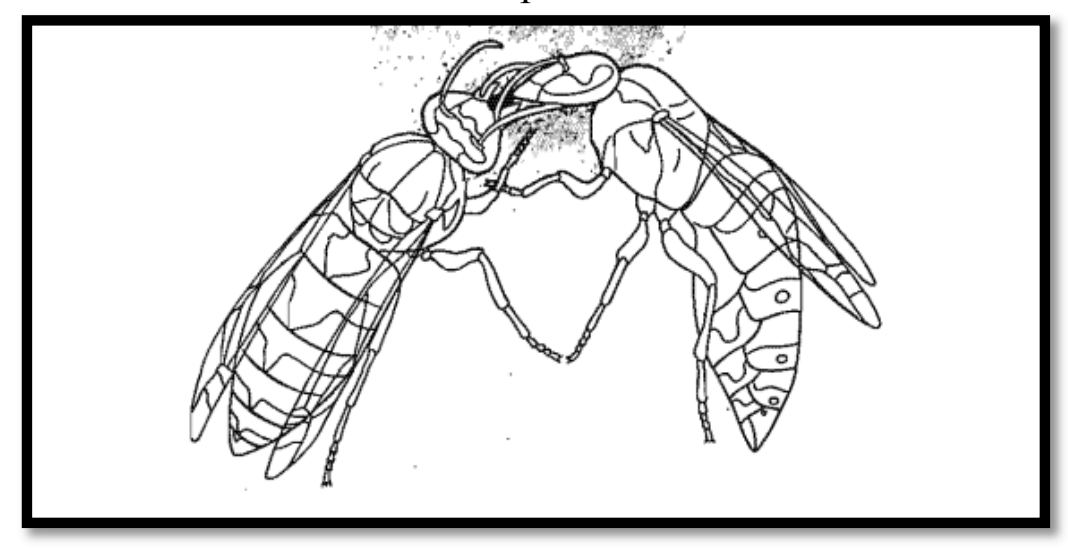

Fonte: Maturana e Varela (1995, p. 212))

Ao abordar a conexão entre ontogênese e filogênese, Radford não está dizendo que esta conexão é direta, como ocorre com a visão do paralelismo recapitulativo exposto na seção anterior. $\mathrm{Na}$ verdade, a postura teórica de Radford está alinhada a uma linha de pensamento que concebe "os seres humanos como consubstanciados com a cultura na qual eles vivem suas vidas". Isto significa que "o que os seres humanos pensam, fazem, sentem, imaginam, esperam e sonham está profundamente enredado em sua cultura." (Radford, 2017, p. 230) Porém, ele também não descarta a existência de uma conexão ${ }^{5}$ entre estes dois domínios. De fato, se tal conexão não existisse, cada geração teria recomeçar toda a história do zero.

Referindo se mais precisamente à matemática, Radford destaca que:

Como a poesia ou a literatura, a matemática - como uma das possíveis formas de reflexão, compreensão e ação sobre o mundo em um dado momento de uma cultura - não é um mero repositório de conteúdos conceituais a serem apropriados por um observador desapaixonado da realidade, mas um produtor de sensibilidades e subjetividades também. (Radford, 2008, p. 165, tradução nossa)

Radford argumenta que deve-se recorrer à história a partir do momento que se tenha consciência do fato de que "essas duas coisas em constante mudança - o que pensamos e o que somos - só foram possíveis graças aos desenvolvimentos filogenéticos das culturas em que vivemos" e que "os significados que nós formamos sobre o nosso mundo têm uma história cultural como pré-condições.” (Radford, 2008, p. 165-166, tradução nossa)

${ }^{5} \mathrm{O}$ posicionamento de Radford em relação à conexão entre ontogênese e filogênese está detalhado em Furinghetti e Radford (2008). 
Retomando o pensamento do crítico literário Mikhail Bakhtin, ele diz que os significados que formamos sobre o mundo só revelam suas profundidades quando entram em contato com significados históricos do passado pois, neste caso, "eles se engajam em um tipo de diálogo que supera a unilateralidade de [nossos] significados particulares." (Bakhtin apud Radford, 2008, p. 166, tradução nossa).

Ele conclui argumentando que:

A matemática, com seu equipamento conceitual tremendamente sofisticado, deveria ser uma janela para entender outras vozes e subjetividades, e compreender a nós mesmos como criaturas historicamente e culturalmente constituídas. (Radford, 2008, p. 166, tradução nossa)

É importante destacar que a posição teórica de Radford sobre o papel da HM na EM está estreitamente ligada ao arcabouço teórico da Teoria da Objetivação $^{6}$ (TO), uma teoria de ensino e aprendizagem da corrente sociocultural com forte abordagem semiótica de sua autoria, na qual a Educação Matemática não é vista como uma espécie de apêndice da matemática, ou seja, como a busca de métodos pedagógicos eficientes para transmitir o saber matemático aos estudantes. Pelo contrário, a Educação Matemática é concebida pela TO como uma prática social, cultural, política e histórica que tem por objetivo a criação de sujeitos éticos, capazes de refletir criticamente e matematicamente sobre os problemas de suas comunidades e do mundo. (D’Amore; Radford, 2017, tradução nossa)

[...] na TO o foco muda de como os estudantes recebem saber (ensino tradicional) e como os estudantes constroem seu próprio saber (construtivismo), para como professores e estudantes produzem [juntos] o saber em sala de aula tendo como pano de fundo a cultura e a história. Contudo o foco também se desloca para a forma como os professores $e$ estudantes coproduzem a si mesmos como sujeitos, em geral, e como sujeitos da educação, em particular. (Radford, 2017, P. 243, grifos nossos)

Esta posição assumida pela TO faz com ela não se limite à dimensão do saber, mas considere igualmente importante a dimensão do ser, do tornar-se (tornar-se alguém com outros). Nesta teoria, qualquer processo em direção ao saber é também um processo de constituição do 'eu'. (Radford, 2008)

\footnotetext{
${ }^{6}$ Um maior aprofundamento sobre os principais elementos da TO pode ser obtido em D'Amore e Radford (2017) e também em vários artigos disponibilizados na página pessoal de Radford (http://luisradford.ca/).
} 
Nesta posição teórica, a História da Matemática torna-se uma necessidade também para que a Educação Matemática, conforme vista pela Teoria da Objetivação, possa cumprir seu papel de formar indivíduos críticos e reflexivos que se posicionam no mundo.

\section{CONSIDERAÇÕES FINAIS}

Iniciamos nosso artigo por um breve histórico do debate envolvendo as relações entre a História da Matemática e a Educação Matemática, o que abarcou o período de finais do século XIX até nossos dias.

A seguir, voltamo-nos para o cenário brasileiro no qual destacamos o trabalho de Antonio Miguel que expõe e analisa os argumentos a favor da presença da HM na EM: motivação, fonte de métodos, instrumento de desmistificação da matemática, meio efetivo de formalização de conceitos matemáticos, instrumento de promoção do pensamento independente e crítico, meio de unificação dos vários campos da matemática, instrumento de promoção de virtudes e valores, instrumento de conscientização epistemológica e, por último, um instrumento que possibilita o resgate da identidade cultural.

Destacamos uma questão importante que emerge ao considerarmos a História da Matemática como recurso pedagógico para o ensino-aprendizagem da Matemática, a saber, a questão do vínculo entre os saberes matemáticos produzidos historicamente e a aprendizagem desses saberes no presente.

Observamos, a partir de estudos realizados pelos pesquisadores Antonio Miguel, Maria Ângela Miorim, Fulvia Furinghetti e Luis Radford, que em grande parte dos argumentos utilizados para defender o potencial pedagógico da História da Matemática, está subjacente uma visão recapitulacionista, na qual o desenvolvimento das ideias de um indivíduo no presente seguiria a mesma sequência e os percalços que seguiram o desenvolvimento destas ideias ao longo do tempo.

Uma vez que muitos, senão todos, destes argumentos continuam em voga atualmente, consideramos pertinente alertar para a importância de um uso consciente da História da Matemática como recurso pedagógico de modo a evitar a admissão e propagação de uma visão recapitulacionista, e para tanto, defendemos que uma condição necessária é adoção de uma posição teórica explícita de como a aprendizagem ocorre e como os saberes matemáticos são produzidos. 
Por fim, apresentamos a posição teórica do pesquisador Luis Radford, que caminha em uma direção completamente diferente da visão recapitulacionista, uma vez que concebe a história como uma necessidade para a compreensão da realidade. Tal posição está ligada ao arcabouço teórico da teoria de ensino-aprendizagem que está desenvolvendo, a Teoria da Objetivação, que concebe a Educação Matemática como uma prática social, cultural, política e histórica que tem por objetivo a criação de sujeitos éticos, capazes de refletir criticamente e matematicamente sobre os problemas de suas comunidades e do mundo e, para tal, faz-se imprescindível a compreensão da realidade que está vivenciando.

\section{AGRADECIMENTOS}

À Coordenação de Aperfeiçoamento de Pessoal de Nível Superior (CAPES) pelo apoio financeiro através do Programa PRODOUTORAL) - Código de Financiamento 001.

\section{REFERÊNCIAS}

Bachelard, G. (1996). A formação do espírito científico: contribuição para uma psicanálise do conhecimento. Rio de Janeiro (Brasil): Contraponto.

Clark, K. et al. (2016). History of mathematics in mathematics education. Recent developments. In: Radford, L.; Furinghetti, F.; Hausberger, T. (Eds.). Proceedings of the 2016 ICME Satellite Meeting of the International Study Group on the Relations Between the History and Pedagogy of Mathematics. Montpellier, France: IREM de Montpellier. p. 135-179.

D’ambrosio, U. (1993). Educação Matemática: Uma Visão do Estado da Arte. Pro-Posições, volume (4, n. 1), p. 9-17.

D’Amore, B.; Radford, L. (2017). Enseñanza y aprendizaje de las matemáticas: problemas semióticos, epistemológicos y prácticos. Bogotá: Universidad Distrital Francisco José de Caldas.

Fauvel, J.; Van Maanen, J. (2000). (Eds.). History in mathematics education: The ICMI Study, New ICMI Study Series, volume (6). Dordrecht: Kluwer.

Furinghetti, F. \& Radford, L. (2008). Contrasts and oblique connections between historical conceptual developments and classroom learning in mathematics. In L. English (Ed.), Handbook of International Research in Mathematics Education, 2nd Edition, p. 626 - 655. New York: Routledge, Taylor and Francis. 
Ilyenkov, E. V. (1982). The dialectic of the abstract and the concrete in Marx's Capital, Moscow: Progress.

Maturana, H.; Varela, F. (1995). A árvore do conhecimento. As bases biológicas do entendimento humano. Campinas: Editorial Psy.

Miguel, A. (1993). Três Estudos sobre História e Educação Matemática. Campinas: UNICAMP, 1993. 285p. Tese (Doutorado) - Faculdade de Educação, Universidade Estadual de Campinas, Campinas.

Miguel, A. (1997). As potencialidades pedagógicas da história da matemática em questão: argumentos reforçadores e questionadores. Zetetiké, Campinas, volume (5, n. 2), p. 73-106.

Miguel, A.; Miorim, M. A. (2004). História na Educação Matemática. Belo Horizonte: Autêntica.

Miguel, A. (2015). Formas especulares e não-especulares de se conceber a relação entre história, epistemologia e educação matemática. Campinas, SP: FE/UNICAMP.

Piaget, J.; García, R. (2011). Psicogênese e história das ciências. Petrópolis: Editora Vozes.

Radford, L. (2008). Beyond Anecdote and Curiosity. The Relevance of the Historical Dimension in the 21st Century Citizen's Mathematics Education. In: Barbin, E.; Stehlíková, N.; Tzanakis, C. (Eds.). Proceedings of the 5th European Summer University. Prague: Vydavatelský servis, Plzeň, p. 163-166.

Radford, L. (2017). A teoria da objetivação e seu lugar na pesquisa sociocultural em educação matemática. In: Moretti, V. D.; Cedro, W. L. (Org.). Educação matemática e a teoria histórico-cultural: um olhar sobre as pesquisas. São Paulo: Mercado das Letras, p. 229-261.

Autoras

Bernadete Barbosa Morey

Estágio pós-doutoral na UNESPRC em História da Matemática (2010), Estágio pós-doutoral na Universidade de Penza, Rússia (2016) em História da Matemática. Estágio pós-doutoral (2017-2018) na Laurentian University, Sudbury, Canadá. Doutorado em Educação Matemática pela Universidade Amizade dos Povos (1992). Mestrado em Matemática pela Universidade Amizade dos Povos (1981). Graduação em Matemática pela Universidade Amizade dos Povos (1979). Lider do Grupo de Pesquisa Matemática e Cultura. Seus interesses em pesquisa são: 1. Teoria da Objetivação, uma teoria de ensino e aprendizagem sociocultural; 2. Relações entre a História da Matemática e a Educação Matemática; 3. Matemática Recreativa e Ensino de Matemática; 4. Matemática Medieval Islâmica. Atualmente é docente Titular aposentada da Universidade Federal do Rio Grande do Norte (RN/Brasil). Mais informações no Currículo Lattes: http://lattes.cnpq.br/7554818862651491. ORCID: https://orcid.org/0000-0003-32530383. E-mail: bernadetemorey@gmail.com 
Valdenize Lopes do Nascimento

Mestrado em Matemática pela Universidade Federal do Ceará (2007). Graduação (2004).

Atualmente é doutoranda do Programa de Pós-Graduação em Ensino de Ciências e Matemática da Universidade Federal do Rio Grande do Norte (RN/Brasil). Docente do Magistério Superior na Universidade Federal Rural do Semiárido - UFERSA em Mossoró-RN. Mais informações no Currículo Lattes: http://Lattes.cnpq.br/3101795420928094. ORCID: https://orcid.org/0000-0003-0984-0519. E-mail: denizeln@ufersa.edu.br 